\title{
Simultaneous quantification of acetaminophen and tryptophan using a composite graphene foam/Zr-MOF film modified electrode
}

Justin Claude Kemmegne-Mbouguen ${ }^{a^{*}}$, Firmin Parfait Tchoumi ${ }^{\text {a }}$,Edwige MouafoTchinda $^{a}$, Henrietta W. Langmi ${ }^{b^{*}}$, Sonwabo E. Bambalaza ${ }^{c}$, Nicholas M. Musyoka ${ }^{c}$, Chrispin Kowenje ${ }^{\mathrm{d}}$, Robert Mokaya ${ }^{\mathrm{e}}$

${ }^{a}$ Laboratoire de Chimie Physique et Analytique Appliquée, Faculté des Sciences, Université de Yaoundé I, B.P. 812 Yaoundé, Cameroon

${ }^{b}$ Department of Chemistry, University of Pretoria, Private Bag, X20 Hatfield, 0028, South Africa

${ }^{c}$ HySA Infrastructure Centre of Competence, Council for Scientific and Industrial Research (CSIR), P. O. Box 395, Pretoria, 0001, South Africa

${ }^{d}$ Department of Chemistry, Maseno University, P. O. Box 333-40105, Maseno, Kenya.

${ }^{e}$ School of Chemistry, University of Nottingham, University Park, Nottingham, NG7 2RD, $\boldsymbol{U K}$

\footnotetext{
*To whom correspondence should be addressed:

e-mail: jkemmeg@yahoo.fr and henrietta.langmi@up.ac.za

phone: + 237666091225 and +27 (0)12 4202800
} 


\section{Abstract}

A graphene foam/zirconium-based metal-organic framework composite (GF/UiO-66) was synthesised and then employed to modify glassy carbon electrodes (GCE). These modified electrodes were successfully used for the simultaneous detection and determination of acetaminophen (AC) and tryptophan (TRYP). The combination of GF and UiO-66 endowed the electrodes with a large surface area, good biological compatibility and stability as well as high selectivity and sensitivity. The linear calibration plots for AC and TRYP were obtained over the range of $0.5-200 \mu \mathrm{M}\left(\mathrm{R}^{2}=0.999\right)$ and $0.5-113 \mu \mathrm{M}\left(\mathrm{R}^{2}=0.999\right)$ with detection limits of $0.07 \mu \mathrm{M}$ and $0.06 \mu \mathrm{M}$, respectively. The modified electrodes were successfully applied for the determination of AC and TRYP in a pharmaceutical preparation and urine, respectively.

Keywords: Graphene foam; UiO-66; modified electrode; Electroanalysis; Acetaminophen; Tryptophan 


\section{Introduction}

Paracetamol (N-acetyl-p-aminophenol or acetaminophen, denoted as AC) is one of the most common analgesic and antipyretic drugs. It is an effective and safe analgesic agent used for the relief of mild to moderate pain associated with headache, backache, arthritis and postoperative pain. In therapeutic doses, it is a suitable alternative when the patient is sensitive to aspirin. Generally, acetaminophen does not exhibit any harmful side effects but in few cases of hypersensitivity and overdose, the formation of some liver and nephrotoxic metabolites were reported ${ }^{1}$. Tryptophan ((2S)-2-amino-3-(1H-indol-3-yl)propanoic acid), denoted as TRYP) is an essential amino acid and is a precursor to the neurotransmitter serotonin and the neurohormone melatonin. Abnormal levels of serotonin and melatonin have been shown to be associated with depression, and Alzheimer's and Parkinson's diseases, respectively ${ }^{2,3}$. It has been shown that the control of dietary intake of TRYP through food or supplements has a positive effect on the regulation of serotonin synthesis and hence in controlling the synthesis of melatonin.

Both AC and TRYP are nitrogen aromatic compounds. AC affects TRYP metabolism by inhibiting tryptophan 2,3-dioxygenase; it can increase the availability of TRYP for generating serotonin ${ }^{3,4}$. Therefore, it is highly desirable to establish sensitive analytical methods for simultaneous determination of AC and TRYP in the human body. For this reason, a lot of detection methods have been established for analysing AC and TRYP, such as spectrophotometry ${ }^{5}$, electrophoresis ${ }^{6}$, mass spectrometry ${ }^{7}$ and high-performance liquid chromatography ${ }^{8}$. Although these methods have been successfully employed, they are timeconsuming, high-cost, and require complicated sample pretreatments. Thus, the development of simple, sensitive, rapid and accurate electrochemical methods for simultaneous determination of acetaminophen and tryptophan is of great importance. However, the simultaneous electrochemical detection of TRYP and AC remains a challenging task due to the slow electron transfer ability of these compounds with the classical working electrode ${ }^{2}$. 
In order to overcome this drawback and enhance the electrochemical response, the classical working electrode should be suitably modified with various modifiers. In this regard, clay materials have been widely used. For example, a zinc hexacyanoferrate clay modified electrode for electroanalysis of tryptophan was previously developed ${ }^{9}$. Subsequently, a sensitive glassy carbon electrode modified with a tetraruthenated cobalt (II) porphyrin intercalated into a smectite clay for simultaneous determination of acetaminophen and tyrosine was also developed ${ }^{10}$. Apart from clay materials, recently, carbon nanomaterials (e.g. carbon nanotubes, carbon black and graphene) have received attention in electrochemical sensors for improving the electrochemical performance due to their powerful conductivity ${ }^{11-}$ 14.

Chemically modified electrodes have attracted considerable interest over the past two decades, as researchers have sought to better control the chemical nature of electrodes. As a result of this interest, numerous sensing devices with better sensitivity and selectivity are continually being developed, with applications in the fields of clinical, industrial and environmental analyses. In order to enhance the analytical capabilities of electrochemical based sensors, electrochemists are actively seeking new electrode materials with improved and advantageous properties in comparison to the more traditional and commonly employed electrode materials, made of noble metals and graphite. Among various materials used for the electrode modification, carbon nanomaterials, and in particular graphene offer beneficial electrochemical properties and open up numerous opportunities to design and implement improved and novel sensors. Graphene is known to possess a unique array of physical, chemical and thermal properties, ${ }^{15}, 16$ and has thus been widely explored as an electrode material ${ }^{17}$. One of the main limitations of using graphene is aggregation of graphene sheets, which typically occurs during immobilisation of graphene onto an electrode surface. To overcome the challenges of graphene aggregation, which limit the performance of graphene 
based electrochemical devices, a 3D graphene foam incorporated into a macroscopic geometric structure for electrochemical use was developed ${ }^{18,}{ }^{19}$. The $3 \mathrm{D}$ graphene enables easier loading of catalysts, enzymes, and nanomaterial to fabricate electrochemical sensors for selective and sensitive quantification of the analytes, and also provides a platform to make different composites by using the porous network.

Metal-organic frameworks (MOFs) are organic-inorganic hybrid crystalline materials formed by coordination of metal ions or clusters to organic ligands ${ }^{20}$. These porous-structure materials comprise of spherical metal coordination clusters coupled with well-defined organic linkers, with both constituents attaining maximum degree of freedom ${ }^{21}$. MOFs have attracted a lot of attention due to their large surface areas and tunable pore sizes, and have been widely explored in the fields of gas storage and separation, catalysis and energy provision ${ }^{22-25}$. Recently, MOFs were used as electrode modifier for electrochemical application owing to the electrochemical activity of the metal ion and well-ordered porous skeleton ${ }^{26}$. MOF modified electrodes have been reported as being efficient for the electrochemical reduction of $\mathrm{CO}_{2}$ and $\mathrm{O}_{2}{ }^{27-29}$ and for the electrochemical sensing of hydrogen peroxide ${ }^{30}$, luteolin ${ }^{31}$, ascorbic acid and haemoglobin ${ }^{32}$, cathecol and hydroquinone ${ }^{26}$. Despite their interesting properties, the utilisation of pure MOFs still suffers from intrinsic deficiencies such as instability in aqueous solution, low sensitivity and poor electron conductivity. To address these shortcomings, heterostructures of MOFs combined with other functional materials have been developed to increase their stability as well as the sensitivity and selectivity of the modified electrode. Thus, Cao et al. modified a glassy carbon electrode with zirconium-based MOF for the detection of luteolin ${ }^{31}$. Xu et al. reported the modification of a solid substrate by a MOFderived porous carbon for the quantification of uric acid, hydroquinone and catechol, ${ }^{33}$ and Rani et al. reported a hydrazine sensor using Zn-MOF-graphene composite modified electrode $^{34}$. In all these studies it has been shown that the electrocatalytic ability of the 
composite improves greatly because of the enhancement of conductivity. Therefore, increasing conductivity of the MOF composite is crucial to further improve the electrocatalytic ability. To improve electron conductivity of MOFs, combination with electrical conductors or integration of guest molecules is an attractive option ${ }^{35}$.

Recently a porous graphene foam/Zr-MOF composite with enhanced properties for hydrogen storage was reported ${ }^{35}$. In the present work, we report the preparation of glassy carbon electrodes modified with a film of graphene foam/Zr-MOF and investigate their response toward AC and TRYP taking advantage of the derived synergistic effect of the two constituent materials.

\section{Experimental}

\subsection{Materials, chemicals and reagents}

Zirconium tetrachloride $\left(\mathrm{ZrCl}_{4}\right.$, Sigma Aldrich, 99.5+\%), terephthalic acid (Sigma Aldrich, 98\%), N,N dimethylformamide (DMF, Sigma Aldrich, 99.8\%), formic acid (HCOOH, Sigma Aldrich, 95+\%), Ni foam (Celmet, Japan: thickness $=1.6 \mathrm{~mm}$, surface area $=7500 \mathrm{~m}^{2} \mathrm{~m}^{-3}$, cell size $=0.5 \mathrm{~mm}, 48-52$ cells per inch) and hydrochloric acid (HCl, Sigma Aldrich, $36.8-$ $38 \%$ ), were used without further purification. All other chemicals used in the electrochemical studies were of analytical grade and used as received. Paracetamol, tryptophan, $\mathrm{K}_{2} \mathrm{HPO}_{4}$, $\mathrm{KH}_{2} \mathrm{PO}_{4}, \mathrm{~K}_{3} \mathrm{Fe}(\mathrm{CN})_{6}$, DMF and $\mathrm{KCl}$ were purchased from $\mathrm{Abcr}$. $\mathrm{CH}_{3} \mathrm{COOH}$ and $\mathrm{CH}_{3} \mathrm{COONa}$ were acquired from Prolabo.

\subsection{Preparation of $\mathrm{Zr}-\mathrm{MOF}$ and graphene foam/Zr-MOF composite}

Zirconium-based MOF (UiO-66) was synthesised as previously reported ${ }^{36}$ with slight modifications. Graphene foam (GF) and GF/UiO-66 composite used in this work were also synthesised as previously reported ${ }^{35}$. In brief, to prepare UiO-66, $0.22 \mathrm{~mol} \mathrm{ZrCl}_{4}$ and $0.22 \mathrm{~mol}$ terephthalic acid were first thoroughly mixed in $50 \mathrm{~mL} \mathrm{DMF}$ and then 100 mol equivalent of 
formic acid was added to the mixture. The synthesis was carried out in an autoclave at $120{ }^{\circ} \mathrm{C}$ for $8 \mathrm{~h}$. The product was washed in DMF and then dried at $90{ }^{\circ} \mathrm{C}$ for $24 \mathrm{~h}$ under vacuum. GF/UiO-66 composite was synthesised following an in-situ two-step growth method consisting of growing UiO-66 onto the GF. In this approach, GF was first prepared as follows: Ni foam of dimension $20 \mathrm{~mm}$ x $20 \mathrm{~mm}$ x $1.6 \mathrm{~mm}$ was put in an alumina crucible and heated at $5{ }^{\circ} \mathrm{C} \cdot \mathrm{min}^{-1}$ to $800{ }^{\circ} \mathrm{C}$ under an Ar flow $\left(0.5 \mathrm{dm}^{3} \cdot \mathrm{min}^{-1}\right)$ in a tube furnace. Then it was annealed at that temperature for $20 \mathrm{~min}$ under $\mathrm{Ar} / \mathrm{H}_{2}\left(0.5 \mathrm{dm}_{3} \mathrm{~min}^{-1} / 0.025 \mathrm{dm}^{3} \cdot \mathrm{min}^{-1}\right)$ to remove any impurities from the surface of the Ni foam. The temperature was ramped under the same conditions to $1000{ }^{\circ} \mathrm{C}$ at $5{ }^{\circ} \mathrm{C} \cdot \mathrm{min}^{-1}$ and then the reaction was conducted for $15 \mathrm{~min}$ with acetylene gas as the carbon source. Thereafter, the sample was allowed to cool slowly to $200{ }^{\circ} \mathrm{C}$ and then rapidly to room temperature. $50 \mathrm{mg} \cdot \mathrm{mL}^{-1}$ solution (in acetone) of Polymethylmethacrylate (PMMA) was then applied as a coating onto the surface of the resultant $\mathrm{Ni}-\mathrm{C}$ composite and the latter was baked at $180{ }^{\circ} \mathrm{C}$ followed by immersion in $3 \mathrm{M}$ $\mathrm{HCl}$ at $80{ }^{\circ} \mathrm{C}$ overnight to remove $\mathrm{Ni}$ by dissolution. This was done to prevent the resultant GF from disintegrating and losing its 3D structure during the etching process. The PMMA matrix was then pyrolysed at $800{ }^{\circ} \mathrm{C}$ for 15 min to yield free-standing GF, which was washed eith deionised waster and dried in air at room temperature. To synthesise the GF/UiO-66 composite, the GF was immersed in the synthesis mixture of UiO-66 for the growth of $\mathrm{Zr}$ MOF crystals at $120^{\circ} \mathrm{C}$ for $8 \mathrm{~h}$ (first step). Thereafter, the resultant GF/UiO-66 composite was immersed in a fresh solution of UiO-66 precursors for the second step growth of Zr-MOF crystals on the surface of the composite at $120^{\circ} \mathrm{C}$ for $8 \mathrm{~h}$.

\subsection{Preparation of the working electrodes}

A glassy carbon electrode (GCE) was used as substrate for the sensor construction. Prior to use, the bare GCE was polished to a mirror-like surface with aqueous alumina slurry of three 
grain sizes $(1,0.3$ and $0.05 \mu \mathrm{m})$ on individual wet polishing cloth, followed by thorough rinsing with distilled water. The electrode was then sonically cleaned in 1:1 water-ethanol for 20 min. to remove any trace of alumina. The UiO-66 and GF/UiO-66 film working electrodes were prepared by drop coating. For this, some microliters of a suspension of UiO-66 or GF/UiO-66, prepared using DMF was dropped onto the glassy carbon surface and allowed to dry at room temperature for about $1 \mathrm{~h}$ and rinsed with distilled water prior to use. The resulting electrodes are denoted as GF/UiO-66/GCE when the composite suspension was used and as UiO-66/GCE when Zr-MOF suspension was used.

\subsection{Instrumentation}

Powder X-ray diffraction (PXRD) patterns were determined using a Rigaku Ultima IV X-ray diffractometer with $\mathrm{CBO}$ technology using Ni-filtered $\mathrm{Cu} \mathrm{K \alpha}$ radiation $(0.154 \mathrm{~nm})$. Morphology analysis was carried out using an Auriga cobra Focused-Ion Beam Scanning Electron Microscope (FIB-SEM). Porosity analysis was obtained by $\mathrm{N}_{2}$ sorption measurements at $77 \mathrm{~K}$ using a Micromeritics ASAP $2020 \mathrm{HD}$ instrument. The IR spectra of pristine UiO-66 and the GF/UiO-66 composite were measured on a benchtop Bruker FTIR spectrometer ALPHA II within a scanning range of 4000 to $400 \mathrm{~cm}^{-1}$ at a scan speed of 24 scans per run. All Electrochemical experiments were performed using $\mu$ Autolab potentiostat/galvanostat linked to a GPES (General Purpose Electrochemical System) electrochemical analysis system. Measurements were performed in a conventional three electrode cell assembly consisting of a saturated calomel electrode (SCE) as reference electrode, a platinum wire counter electrode and the modified glassy carbon as working electrode. Electrochemical characterisation was evaluated by cyclic voltammetry in $\left[\mathrm{Fe}(\mathrm{CN})_{6}\right]^{3-} 0.5 \mathrm{mM}$ and by electrochemical impedance spectroscopy in $\left[\mathrm{Fe}(\mathrm{CN})_{6}\right]^{3-14-} 0.5 \mathrm{mM}$ 
in $\mathrm{KCl} 0.1 \mathrm{M}$. Differential pulse voltammetry (DPV) was used for paracetamol and tryptophan determination.

\section{Results and discussion}

\subsection{Physicochemical characterisation of GF/UiO-66 composite}

The properties of the composite and component materials employed in this study were described in a previous work relating to hydrogen storage applications ${ }^{35}$. Powder XRD patterns confirmed that the presence of GF in the precursor solution of the MOF did not prevent the growth of UiO-66 crystals as the diffraction peaks belonging to UiO-66 were found in the XRD patterns for both pristine UiO-66 and the GF/UiO-66 composite (Fig. S1) ${ }^{35}$. Furthermore, the graphene crystalline phase (002) was observed in the XRD pattern of the GF/UiO-66 composite. BET surface areas for UiO-66 and GF/UiO-66 were 1258 and 1070 $\mathrm{m}^{2} \mathrm{~g}^{-1}$, respectively (Fig. S2) ${ }^{35}$, which are in good agreement with previously reported values

35. The decrease in the BET surface area of the composite relative to the pristine MOF is attributed to the macroporosity associated with the GF. The FTIR spectra and SEM images of the UiO-66 and GF/UiO-66 composite are shown in figure 1.

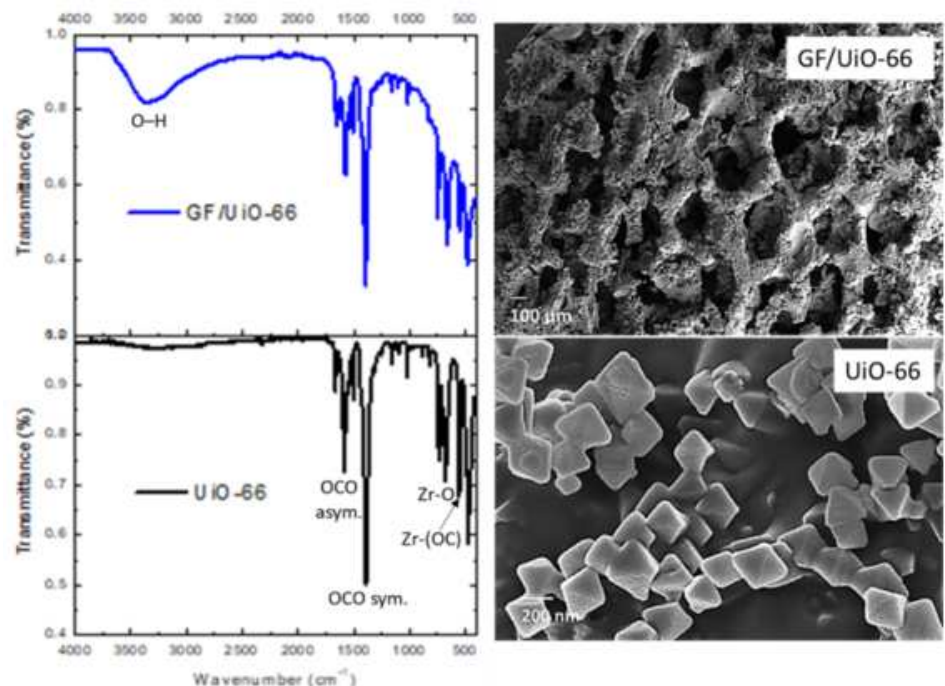

Fig. 1 FTIR spectra and SEM images of pristine UiO-66 (bottom images) in comparison to GF/UiO-66 composite obtained via a two-step growth of UiO-66 crystals onto GF (top images). The SEM images for UiO-66 and GF/UiO-66 are measured at $20000 \mathrm{X}$ and $1000 \mathrm{X}$ magnification respectively. 
The FTIR spectrum of UiO-66 shows the characteristic vibration bands associated with UiO66. The bands at ca. 1586 and $1391 \mathrm{~cm}^{-1}$ are assigned to the carboxylate asymmetric stretching and carboxylate symmetric stretching, respectively. The vibrational bands at ca. 679 and $554 \mathrm{~cm}^{-1}$ are associated with $\mathrm{Zr}-\mathrm{O}$ stretch vibrations present in the UiO-66 inorganic nodes and $\mathrm{Zr}-(\mathrm{OC})$ asymmetric stretching, respectively. When the FTIR spectrum of GF/UiO66 is compared with that of UiO-66, a good agreement both in position and in relative intensity of the bands was generally found implying that the introduction of GF did not interfere with the chemical structure of UiO-66. The only significant difference between the two spectra is the broad band at $3800-3000 \mathrm{~cm}^{-1}$, attributed to stretching of hydrogen-bonded O-H groups. This band is enhanced in the GF/UiO-66 composite since the GF foam might contain defects as previously reported ${ }^{35}$. It can be clearly seen from the SEM image that the UiO-66 MOF consists of well-defined octahedral shaped crystals, noting that the morphology and size of the crystals are consistent with the synthesis time of $8 \mathrm{~h}$ employed here instead of $24 \mathrm{~h}$ synthesis time that would result in micro-sized crystals ${ }^{36}$. The morphology of the synthesised UiO-66 was corroborated by TEM images (Fig. S3). Both the XRD and IR data indicate that the GF/UiO-66 composite was successfully synthesised following our in-situ two-step growth method. As observed in the SEM image for the composite, the GF, which consists of a macroporous structure, was covered by UiO-66 crystals and the distribution of the crystals was observed on the surface as well as within the macropores of the GF network.

\subsection{Electrochemical characterisation of GF/UiO-66 film}

A preliminary investigation of the $\mathrm{GF} / \mathrm{UiO}-66$ composite toward an anionic probe was carried out in order to test its ability to form a stable and thin film on the GCE surface and to access the surface area of the modified electrode. This was done by examining the electrochemical behaviour of $\left[\mathrm{Fe}(\mathrm{CN})_{6}\right]^{3-}$ ions in $0.1 \mathrm{M} \mathrm{KCl}$ solution at the $\mathrm{GF} / \mathrm{UiO}-66$ and $\mathrm{UiO}-66$ film 
modified glassy carbon, by recording a series of cyclic voltammograms in diluted solution of $\left[\mathrm{Fe}(\mathrm{CN})_{6}\right]^{3-}$. Figure 2 shows multisweep cyclic voltammograms recorded at the GF/UiO-66 (Fig. 2A) and UiO-66 (Fig. 2B) modified GCE and at the unmodified GCE (Fig. 2C).For modified and unmodified glassy carbon electrodes, well defined diffusion controlled redox behavior with $\mathrm{Fe}(\mathrm{CN}) 6^{3-}$ with a constant steady state was recorded upon repetitive scanning. It was also observed that the steady current obtained at GF/UiO-66 /GCE was greater than that recorded at GCE and its $\triangle \mathrm{E}$ was $107 \mathrm{mV}$ lower than that at bare GCE. The increase in current peak as well as low $\Delta \mathrm{E}$ recorded at modified GCE compared with the corresponding values at bare GCE indicated that the electron transfer of ferricyanide on GCE was enhanced by the modification using UiO-66 and GF/UiO-66. 

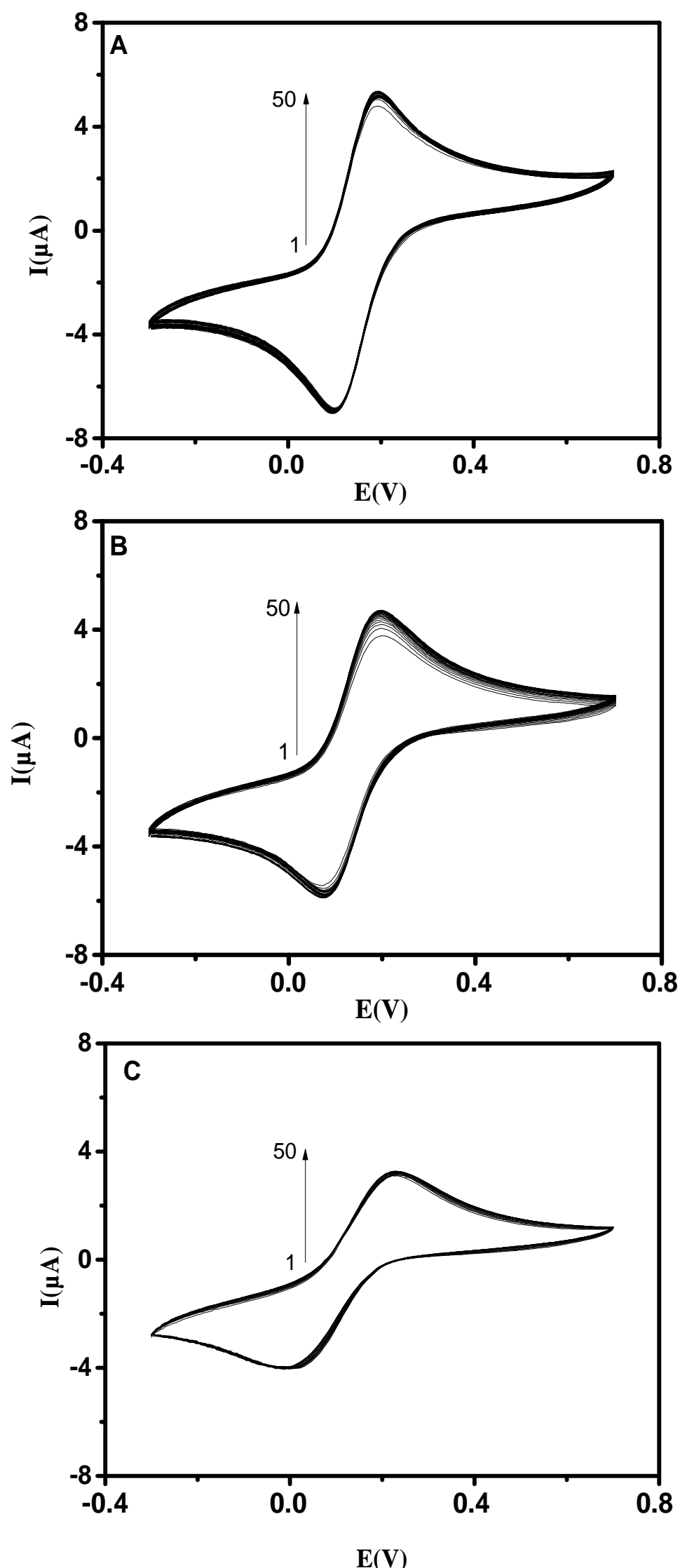

Fig. 2 Multisweep cyclic voltammograms recorded at: (A) GF/UiO-66/GCE, (B)UiO66/GCE, and (C) bare GCE in $0.1 \mathrm{M} \mathrm{KCl}$ containing $0.5 \mathrm{mM} \mathrm{Fe}(\mathrm{CN})_{6}{ }^{3-}$ at scan rate: 50 $\mathrm{mV} \cdot \mathrm{S}^{-1}$ 
At $\mathrm{GF} / \mathrm{UiO}-66 / \mathrm{GCE}$, the CVs recorded were centered at $\left(E^{\circ \prime}=1 / 2\left(E_{\mathrm{pc}}+E_{\mathrm{pa}}\right)\right)=+0.146 \mathrm{~V}$; with peak-to-peak separation values of $\left(\Delta E_{\mathrm{p}}=E_{\mathrm{pc}}-E_{\mathrm{pa}}\right)=0.093 \mathrm{~V}$. Although the steady currents recorded at $\mathrm{GF} / \mathrm{UiO}-66 / \mathrm{GCE}$ and at $\mathrm{UiO}-66 / \mathrm{GCE}$ were in the same order of magnitude, the peak to peak separation recorded at GF/UiO-66/GCE was lower by $\sim 23 \mathrm{mV}$ compared with that obtained at $\mathrm{UiO}-66 / \mathrm{GCE}$ (centered at $+0.138 \mathrm{~V}$ ) at a scan rate of $50 \mathrm{mV} \cdot \mathrm{s}^{-1}$, suggesting that the diffusion of the probe is less difficult at GF/UiO-66 /GCE. The results could be attributed to the synergistic effect of the GF/UiO-66 composite, which enhanced the whole interfacial conductivity by increasing the effective area on the electrode surface.

The effective surface area of the GF/UiO-66 /GCE and UiO-66 /GCE was evaluated using $\mathrm{K}_{3}\left[\mathrm{Fe}(\mathrm{CN})_{6}\right]$ as a probe based on Randles-Sevcik equation. The experiment was performed in $5 \times 10^{-4} \mathrm{M} \mathrm{K}_{3}\left[\mathrm{Fe}(\mathrm{CN})_{6}\right]$ solution at various scan rates (Fig. S4). For a reversible process, the following equation can be utilised ${ }^{37-39}$ :

$$
\mathrm{Ip}=2.69 \times 10^{5} \times\left(\mathrm{D}_{0}\right)^{1 / 2} \cdot \mathrm{A} \cdot \mathrm{v}^{1 / 2} \cdot \mathrm{n}^{3 / 2} \cdot \mathrm{C}_{0}
$$

Where $\mathrm{n}, \mathrm{A}, \mathrm{Co}$, Do, and $\mathrm{v}$ are the number of electrons, electrode area, concentration, diffusion coefficient, and scan rate, respectively. Here, for $\left[\mathrm{Fe}(\mathrm{CN})_{6}\right]^{3-} /\left[\mathrm{Fe}(\mathrm{CN})_{6}\right]^{4-}, \mathrm{n}=1, \mathrm{C}_{0}=$ $5.10^{-7} \mathrm{~mol} \mathrm{~cm}^{-3}$ and $\mathrm{D}_{0}=1 \times 10^{-5} \mathrm{~cm}^{2} \mathrm{~s}^{-1} 37$. Therefore, the calculated effective surface area of the GF/UiO-66 modified electrode is $0.064 \mathrm{~cm}^{2}$. This surface is 1.5 times greater than that of UiO-66/GCE and 1.9 times that of the bare glassy carbon electrode.

Electrochemical impedance spectroscopy is a powerful tool for studying the capability of electron transfer on the surface of different electrodes. Figure 3 shows the typical results of EIS for the bare GCE (curve a), UiO-66/GCE (curve b) and GF/UiO-66/GCE (curve c), respectively. Obviously, the profile for the bare GCE and UiO-66/GCE exhibited the largest semicircle, indicating the lowest electron transfer rate. Interestingly, the curve of the GF/UiO66/GCE exhibited a slightly smaller radius of the semicircles compared with the bare GCE 
and UiO-66/GCE, which showed that the presence of GF/UiO-66 could effectively accelerate the electron transfer. The behaviour of the GF/UiO-66/GCE demonstrated that the composite is able to synergistically accelerate the electron transfer on the electrode surface, which is very important for improving the sensitivity of electrochemical detection.

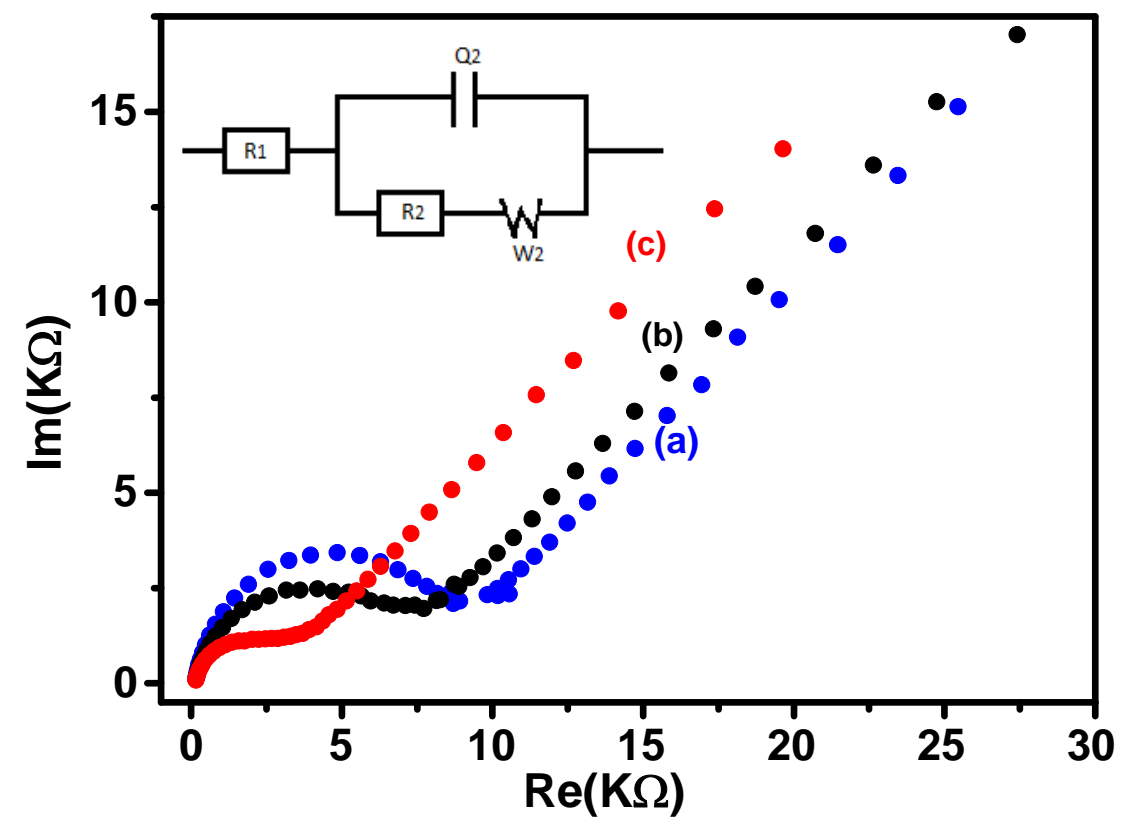

Fig. 3 Electrochemical impedance spectra of (a) GCE, (b) UiO-66/GCE and (c) GF/UiO$66 / \mathrm{GCE}$ in $0.1 \mathrm{M} \mathrm{KCl}$ containing $0.5 \mathrm{mM} \mathrm{Fe}(\mathrm{CN})_{6}{ }^{3-/ 4-}$. The inset shows the equivalent circuit of $\mathrm{GF} / \mathrm{UiO}-66 / \mathrm{GCE}$

\subsection{Electrocatalytic properties of GF/UiO-66/GCE}

The electrochemical behaviour of $G F / U i O-66 / \mathrm{GCE}$ electrode was studied in the presence of AC and TRYP. Fig. 4 shows the cyclic voltammograms obtained at GF/UiO-66/GCE in the absence of AC (curve a in Fig. 4A) and TRYP (curve a' in Fig. 4B) and in the presence of $51.2 \mu \mathrm{M}$ of $\mathrm{AC}$ (curve $\mathrm{b}$ in Fig. 4A) and $12 \mu \mathrm{M}$ of TRYP (curve b' in Fig. 4B). 

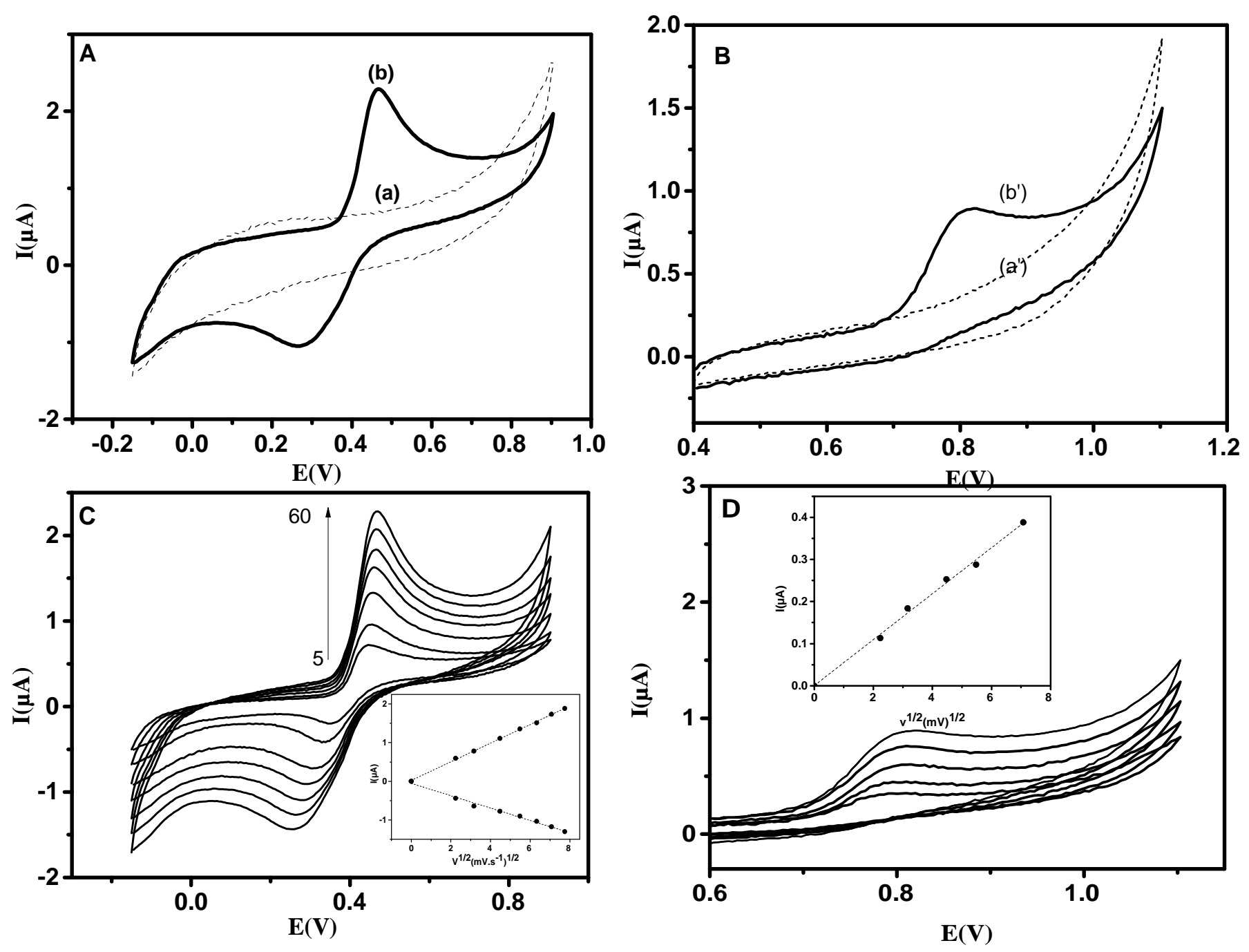

Fig. 4 Cyclic voltammograms of GF/UiO-66/GCE recorded in $\mathrm{AB}$ (pH 4): (A) in the absence (curve a) and in the presence of $51.2 \mu \mathrm{M} \mathrm{AC} \mathrm{(curve} \mathrm{b),} \mathrm{(B)} \mathrm{in} \mathrm{the} \mathrm{absence} \mathrm{(curve} \mathrm{a')} \mathrm{and} \mathrm{in}$ the presence of $12 \mu \mathrm{M}$ TRYP (curve b'). (C) and (D) show CVs in the same conditions as in (A) and (D) respectively, at different scan rates. Insets show plot of peak current versus the square root of scan rate $\left(\mathrm{v}^{1 / 2}\right)$.

In the absence of AC and TRYP, no peak was observed on the recorded voltammograms. When AC was sparingly added to the electrolytic solution, a pair of strong redox peaks was observed and centered at $+0.367 \mathrm{~V}$ with $\Delta E_{\mathrm{p}}=194 \mathrm{mV}$, corresponding to a quasi-reversible behavior in aqueous medium. In addition to the increase of peak intensity in comparison to the voltammogram recorded at bare GCE (Fig. S5 A, curve a), the anodic peak potential shifted from $+0.540 \mathrm{~V}$ to $+0.464 \mathrm{~V}$, meanwhile the cathodic peak potential positively shifted 
from $+0.012 \mathrm{~V}$ to $+0.266 \mathrm{~V}$, leading to a dramatic reduction in $\Delta \mathrm{Ep}$ of $334 \mathrm{mV}$, which can be attributed to the synergistic effect of GF/UiO-66 on the GCE. These results demonstrated that the overpotential was remarkably lowered and the electrochemical reversibility of $\mathrm{AC}$ at GF/UiO-66 /GCE was strongly improved, indicating that the modification of the GCE using GF/UiO-66 composite can significantly accelerate electron transfer.

TRYP exhibits an oxidation peak at $+0.812 \mathrm{~V}$ at GF/UiO-66/GCE, with an increase in anodic peak current, compared to that of bare GCE (Fig. S5, curve b'). The remarkable enhancement of anodic peak current provides clear evidence of the catalytic effect of the GF/UiO-66 composite. On reverse scan, no reduction peak was observed, indicating that the electron transfer process at the electrode surface of the analyte is an irreversible process.

Figures $4 \mathrm{C}$ and $4 \mathrm{D}$ show the effect of the potential scan rate on the electrochemical oxidation of AC and TRYP at GF/UiO-66/GCE. For the two analytes, the oxidation current $\left(I_{\mathrm{p}}\right)$ versus the square root of the potential scan rate $\left(\mathrm{v}^{1 / 2}\right)$ was plotted and resulted in a straight line as shown in the insets of Fig. $4\left(\mathrm{R}^{2}=0.998\right.$ for $\mathrm{AC}$ and $\mathrm{R}^{2}=0.992$ for TRYP). This linearity suggests that the electrooxidation process of both compounds (AC and TRYP) at $\mathrm{GF} / \mathrm{UiO}-66 / \mathrm{GCE}$ in the studied scan rate interval is controlled by mass transport.

The log of peak current versus log scan rate was also plotted (Fig. 5). It is well known that for this kind of plot, when the slope is 0.5 , the electrochemical reaction is controlled by diffusion, and when equal to 1 , the electrochemical process is governed by adsorption and diffusion. 

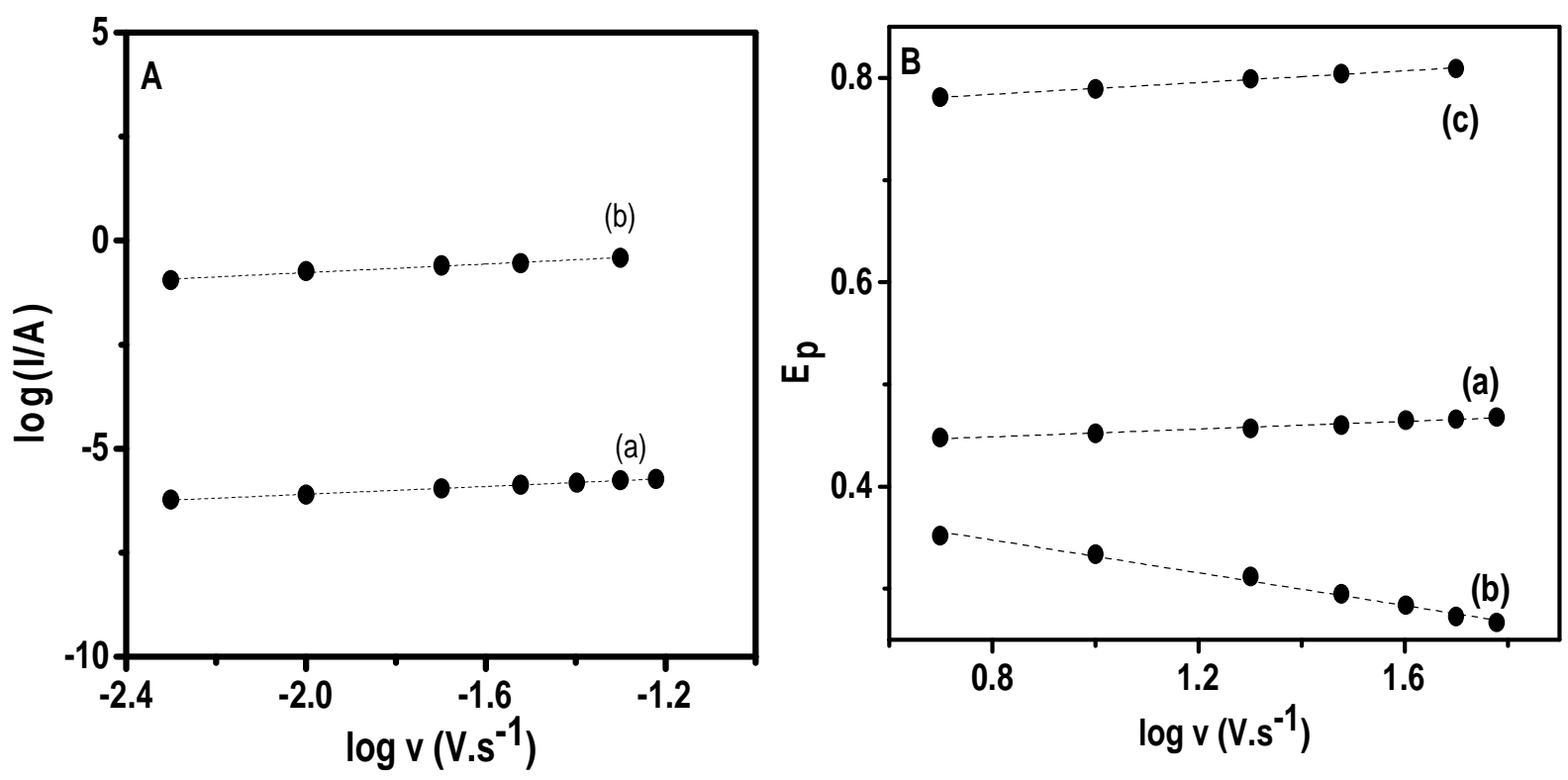

Fig. 5 Plots of: (A) $\log$ I versus $\log v$ for AC (curve a) and TRYP (curve b) and (B) Ep versus $\log v$ for AC (curve a and b) for TRYP (curve c)

In the present study, for AC and TRYP the plots of log peak current obtained using the modified electrode versus log of scan rate were linear $\left(\mathrm{R}^{2}=0.999\right)$ and the slopes were found to be 0.47 (curve a, Fig. 5A) and 0.51 (curve b, Fig. 5A) for $51.2 \mu \mathrm{M}$ of AC and $12 \mu \mathrm{M}$ TRYP, respectively. These results are close to 0.5 , indicating that the electrochemical oxidation of these two compounds at GF/UiO-66/GCE electrode was predominately governed by diffusion ${ }^{10}$ and their surface was not fouled by these analytes.

In order to determine the electron transfer rate, a plot of $\mathrm{E}_{\mathrm{p}}$ versus $\log v$ was obtained (as seen in Fig. 5B). For $\mathrm{AC}$ and TRYP, the peak potential $\mathrm{E}_{\mathrm{pa}}$ and/or $\mathrm{E}_{\mathrm{pc}}$ were linearly dependent on the $\log v$ with the regression equations:

For AC (Fig. 5B (curve a for oxidation and curve $\mathrm{b}$ for reduction)):

$$
\begin{array}{ll}
E_{\mathrm{pa}}=0.0189 \log v+0.434 & \left(R^{2}=0.984\right) \\
E_{\mathrm{pc}}=-0.08 \log v+0.421 & \left(R^{2}=0.989\right)
\end{array}
$$

For Tryp (Fig. 5B, curve c) ): 
According to Laviron theory ${ }^{40}$ for reversible process, a plot of $E_{\mathrm{p}}$ versus $\log v$ yields two straight lines with slopes of $2.3 R T /(1-\alpha) n F$ for oxidation peak and $-2.3 R T / \alpha n F$ for reduction peak. Where $\alpha$ is the electron transfer coefficient, $n$ is the number of electrons involved in the rate-controlling step, $R, T$ and $F$ are the gas constant, temperature and Faraday constant, respectively. From the slopes of the two straight lines of $E_{\mathrm{p}}$ versus $\log v$, the charge transfer coefficient, $\alpha$ was calculated to be 0.2 and the number of transferred electrons $n$ was found to be 4 , indicating that four electrons are involved in its electrochemical redox. Interestingly, at UiO-66/GCE, $\alpha$ was found to be 0.4 (see Fig. S5 B) implying that the number of electrons involved in AC electrochemical redox is two as reported in literature ${ }^{10}$, half of the number of electrons involved when the composite modified GCE was used. This suggests that overall oxidation process of $\mathrm{AC}$ is complex. While the reasons for this complexity are unclear, it is not unexpected given the extraordinary rich redox properties of GF, with the possibility that it could enable electron transfer from AC molecules in addition to the porous nature of UiO-66. Further studies are needed to fully explain the physicochemical role of the MOF, especially in terms of the interaction between UiO-66 and GF on the one hand, and AC and the constituents of the composite on the other hand.

For the totally irreversible diffusion controlled process of TRYP, a Tafel slope was determined using the following equation ${ }^{40}$ :

$$
E p a=K+\left(\frac{b}{2}\right) \log v
$$

Based on this equation, $\mathrm{b} / 2$ is the slope of $\mathrm{E}_{\mathrm{p}}$ versus $\log v$ where $\mathrm{b}$ is the Tafel slope and $v$ the potential scan rate. The slope of $E_{p}$ versus $\log v$ (Eq. 5) was found to be 0.029 (curve c, Fig 5B), so $b=2 \times 0.029$ i.e., 0.058 for the oxidation of TRYP at GF/UiO-66/GCE electrode. This slope is close to that obtained with $\mathrm{UiO}-66 / \mathrm{GCE}\left(0.028, \mathrm{R}^{2}=0.986\right.$ as seen in inset Fig. S5 D). 
The slope obtained for GF/UiO-66/GCE also indicates that a two-electron transfer process was the rate determining step with a transfer coefficient $\alpha=0.41$.

\subsection{Parameters optimisation of GF/UiO-66/GCE}

The voltammetric behaviour of AC and TRYP was investigated using differential pulse voltammetry (DPV) at the GF/UiO-66/GCE electrode prepared as indicated in section 2.3. Figure 6 shows differential pulse voltammograms recorded at bare GC (curve a), at UiO66/GCE (curve b) and at GF/UiO-66/GCE (curve c), in $0.1 \mathrm{M}$ acetate buffer solution (pH 4.0) prepared in $0.1 \mathrm{M} \mathrm{KCl}$ solution (denoted as $\mathrm{AB}$ ) and containing $17 \mu \mathrm{M}$ of both $\mathrm{AC}$ and TRYP.

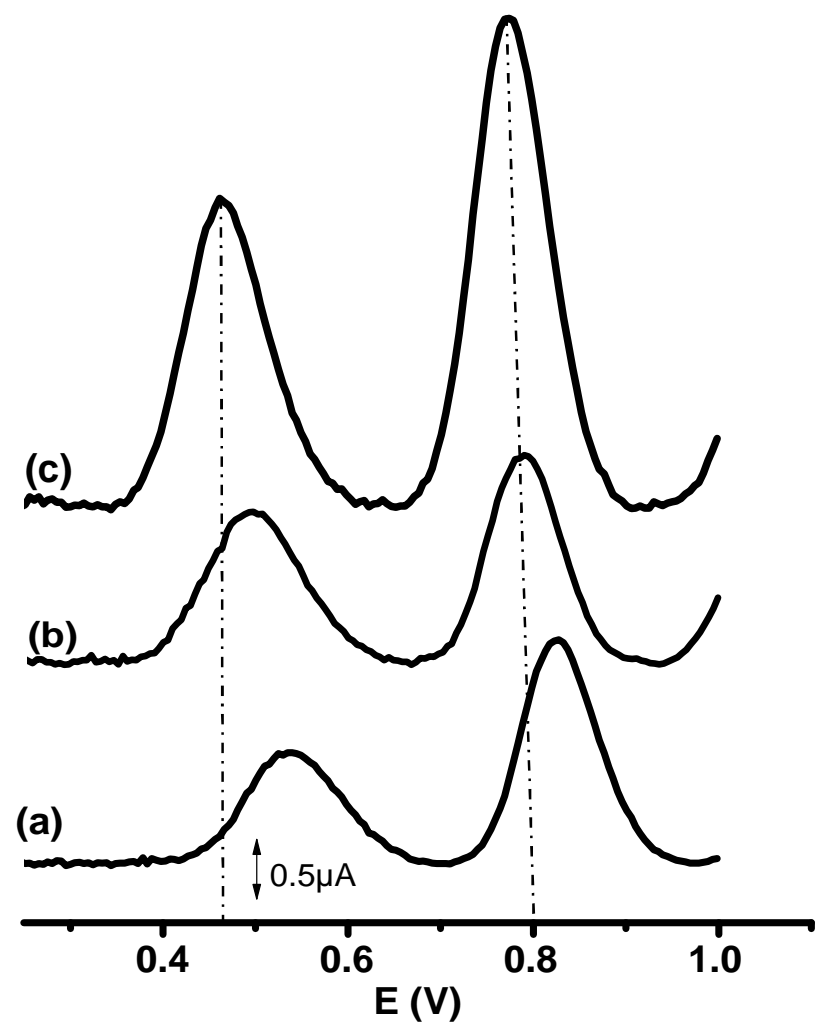

Fig. 6 Differential pulse voltammogramms recorded in $\mathrm{AB}(\mathrm{pH} 4)$ containing $17 \mu \mathrm{M} \mathrm{AC}$ and TRYP at bare GCE (curve a), UiO-66/GCE (curve b), GF/UiO-66/GCE (curve c) 
Using either a bare GCE (curve a) or a UiO-66 and GF/UiO-66 modified electrode GCE (curve b and c, respectively), two well resolved peaks appeared. At bare GC the two peaks, corresponding to the oxidation of AC and TRYP, emerged at $+0.534 \mathrm{~V}$ and $+0.826 \mathrm{~V}$, respectively. At UiO-66 modified electrode, although the oxidation current was nearly the same for the two analytes, the corresponding peak potentials were negatively shifted by 40 $\mathrm{mV}$ for $\mathrm{AC}$ and $37 \mathrm{mV}$ for TRYP. Curve $\mathrm{c}$ shows that the modification of GC electrode with the GF/UiO-66 composite film also gave two well-defined oxidation peaks at potentials of ca. $+0.463 \mathrm{~V}$ and $+0.773 \mathrm{~V}$, corresponding to the oxidation of AC and TRYP, respectively. These peak potentials are negatively shifted by $71 \mathrm{mV}$ and by $52 \mathrm{mV}$ for AC and TYRP, respectively, compared with oxidation signal recorded at bare GC. Regarding the oxidation peak current, the peak height obtained with GF/UiO-66 /GCE is twice that obtained with bare GCE and UiO-66 modified electrode. This is probably due to a combination of the electrical properties of GF and the porosity of UiO-66.

A critical parameter likely to affect the sensitivity of the sensor prepared with the composite is the film thickness, which can be tuned by varying the amount of deposited material. The effect of the suspension volume allowed to dry on the electrode surface was investigated in the range of $1.5-7.5 \mu \mathrm{L}\left(2 \mathrm{mg} . \mathrm{L}^{-1}\right)$ by means of the DPV for AC and TRYP in AB. Figure S6 A shows the effect of the amount of composite deposited on GCE on the DPV response towards AC (curve a) and TRYP (curve b). The response of the sensor was found to increase with the amount of deposited material up to $5 \mu \mathrm{L}$ of the GF/UiO-66 suspension and then levelled off before decreasing for larger amounts of deposited material. The increment of oxidation current of the two analytes can be assigned to the increase of the electrode surface porosity, and specifically to enhancement of the effective surface area of the modified electrode. The slight decrease in the sensor response above the threshold value $(5 \mu \mathrm{L})$ could result from a larger film thickness, which could make the mass transfer process for the 
analytes sluggish. As a result, $\mathrm{V}=5 \mu \mathrm{L}$ of the $\mathrm{GF} / \mathrm{UiO}-66$ suspension was selected as the amount of suspension of the composite to be used to prepare the composite film electrode.

The influence of the $\mathrm{pH}$ value of the supporting electrolyte on the redox process of AC and TRYP was also studied. The differential pulse voltammetry of $22 \mu \mathrm{M}$ of both AC and TRYP at different $\mathrm{pH}$ values is demonstrated in Figure S6 B. It reveals that both the anodic peak currents for the analytes increased gradually with an increase in $\mathrm{pH}$, peaked at a $\mathrm{pH}$ of 4.0 and then decreased significantly with a further increase in $\mathrm{pH}$. After $\mathrm{pH} 4$, the electrochemical responses decrease substantially. This $\mathrm{pH}$ is close to the $\mathrm{pH}(3.8)$ of neutral UiO-66 aqueous suspension ${ }^{41}$. From the above results, a $\mathrm{pH}$ of 4.0 was chosen as the optimum solution $\mathrm{pH}$ for further experiments.

\subsection{Determination of TRYP and AC at GF/UiO-66/GCE}

\subsubsection{Individual determination of AC and TRYP}

The electrochemical response of both AC and TRYP was separately investigated with a GF/UiO-66/GCE electrode. Figures 7A and B show the DPV of AC at $+0.44 \mathrm{~V}$ (Fig. 7A) and TRYP at $+0.81 \mathrm{~V}$ (Fig. 7B) when increasing amounts of these analytes are added in AB solution ( $\mathrm{pH}$ 4). In both cases each peak current observed represents a constant increase of concentration of the analyte. As shown in the insets of both figures, a proportional relationship exists between the peak height and the added concentration. The linear responses for the individual determination of TRYP and AC were observed in the concentration ranges of $0.5-113 \mu \mathrm{M}\left(\mathrm{R}^{2}=0.999\right)$ for AC and $0.5-113 \mu \mathrm{M}\left(\mathrm{R}^{2}=0.994\right)$ for TRYP. From the inset of these figures, the sensitivity of GF/UiO-66/GCE electrode was calculated as $0.027 \mu \mathrm{A} / \mu \mathrm{M}$ and $0.037 \mu \mathrm{A} / \mu \mathrm{M}$ for $\mathrm{AC}$ and TRYP, respectively. 

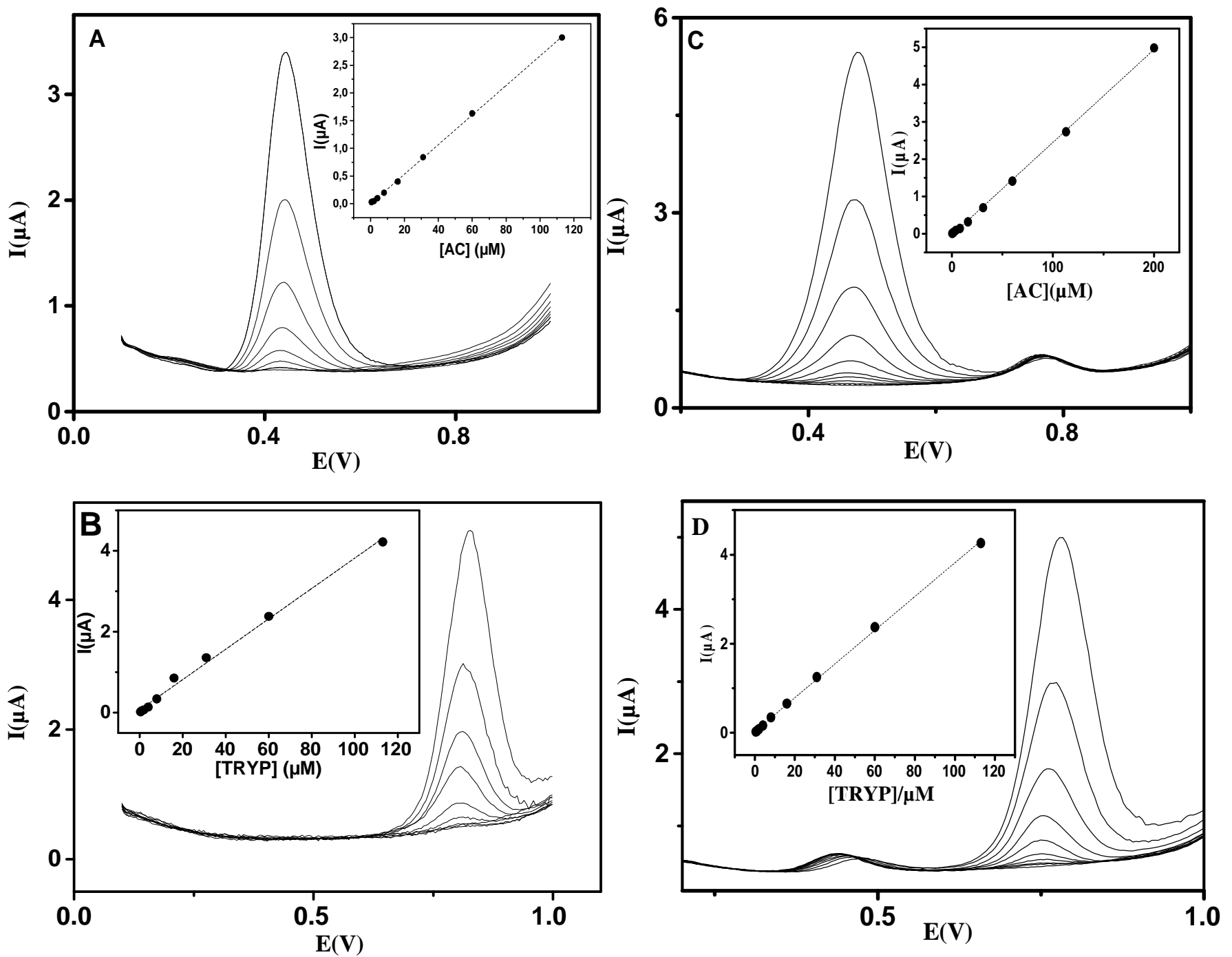

Fig. 7 Differential pulse voltammograms recorded in $\mathrm{AB}(\mathrm{pH} 4)$ at GF/UiO-66/GCE with successive addition of: (A) AC and (B) TRYP. C and D show DPVs recorded at GF/UiO66/GCE in the same electrolyte containing: (C) a constant concentration of TRYP $(8 \mu \mathrm{M})$ to which was added increasing amounts of $\mathrm{AC}$ and $(\mathbf{D})$ a constant concentration of $\mathrm{AC}(8 \mu \mathrm{M})$ to which successive addition of TRYP was employed. The insets show the corresponding calibration curve.

\subsubsection{Simultaneous determination of $A C$ and TRYP}

The electrochemical response of both $\mathrm{AC}$ and TRYP was investigated using a GF/UiO66/GCE electrode. The individual determination of AC and TRYP was studied by means of the DPV method in which the concentration of one compound was increased in the presence of a constant concentration of the other compound. Figures $7 \mathrm{C}$ and D show the DPV of AC at 
$+0.47 \mathrm{~V}$ and TRYP at $+0.77 \mathrm{~V}$, respectively when increasing amounts of these analytes are added in $\mathrm{AB}$ solution ( $\mathrm{pH}$ 4). In both cases each peak current observed represents a constant increase of concentration of the analyte, and it is worth noting that the peak potential of both AC and TRYP remained fairly constant, while the oxidation peak currents increased in line with concentration. This indicates that the oxidation reactions took place independently. As shown in the insets of both figures, a proportional relationship exists between the peak height and the added concentration. The linear responses for the individual determination of $\mathrm{AC}$ and TRYP were observed in the concentration ranges of $0.5-200 \mu \mathrm{M}\left(\mathrm{R}^{2}=0.999\right)$ and $0.5-113$ $\mu \mathrm{M}\left(\mathrm{R}^{2}=0.999\right)$ with the detection limits of $0.07 \mu \mathrm{M}$ and $0.057 \mu \mathrm{M}(\mathrm{S} / \mathrm{N}=3)$, respectively. The sensitivity of $\mathrm{GF} / \mathrm{UiO}-66 / \mathrm{GCE}$ electrode was calculated as $0.025 \mu \mathrm{A} / \mu \mathrm{M}$ and $0.038 \mu \mathrm{A} / \mu \mathrm{M}$ for $\mathrm{AC}$ and TRYP, respectively. The corresponding detection limits and response ranges of these sensors are listed in Table 1 for comparison with those reported in the literature. It is clear that the GF/UiO-66/GCE sensors showed wider linear ranges and lower detection limits for determination of AC and TRYP.

The excellent electrocatalytic activities of the composite also favour the simultaneous determination of TRYP and AC using the GF/UiO-66/GCE. Figure S7 depicts the DPV curves of various TRYP and AC concentrations at GF/UiO-66/GCE. In the presence of both analytes, two well-resolved independent anodic peaks were observed for AC and TRYP, and the anodic peak separation $\left(\Delta \mathrm{E}_{\mathrm{AC}-\mathrm{TRYP}}\right)$ between these two analytes was found to be ca. 300 $\mathrm{mV}$. This peak potential separation is very close to that obtained when each analyte oxidation was investigated independently. These results demonstrate that the GF/UiO-66/GCE sensors may be a promising candidate for simultaneous determination of AC and TRYP in their binary mixture without cross interference. When the concentrations of the two species increased synchronously, the individual peak currents increase concomitantly. The insets of Figure S7 shows that the oxidation currents of AC and TRYP were proportional to their 
concentration $\left(\mathrm{R}^{2}=0.999\right)$ with a slope of $0.026 \mu \mathrm{A} / \mu \mathrm{M}$ and $0.042 \mu \mathrm{A} / \mu \mathrm{M}$, respectively, which are very close to that obtained with individual analyte. To evaluate the influence of some potential interference on the determination of AC and TRYP, various foreign species were added into $0.1 \mathrm{M} \mathrm{AB}$ containing $46.3 \mu \mathrm{M}$ of both TRYP and AC, including possible inorganic ( $0.01 \mathrm{~mol} \mathrm{~L}^{-1}$ of $\mathrm{Ca}^{2+}, \mathrm{Mg}^{2+}$ or $\left.\mathrm{Zn}^{2+}\right)$ and organic (folic acid, ascorbic and uric acid, starch, or glucose) interferences. The interferences and the response of the sensor toward these analytes was studied and found not to interfere in the determination of AC and TRYP (signal change below 5\%), except uric acid whose response drastically affects AC response. 
Table 1: Comparison of some modified electrodes for the determination of AC and TRYP

\section{Electrodes \\ Linear range $(\mu \mathrm{M})$ \\ Detection limite $(\mu \mathrm{M})$ \\ References}

\begin{tabular}{|c|c|c|c|}
\hline \multicolumn{4}{|l|}{$\overline{\mathrm{AC}}$} \\
\hline MWCNTs-NHNPs-MCM-41/GCE & $0.05-30$ & 0.01 & 3 \\
\hline Nafion- $\mathrm{TiO}_{2}-\mathrm{GR} / \mathrm{GCE}$ & $1-100$ & 0.21 & 42 \\
\hline NiO-CuO-GR/GCE & $4-400$ & 1.33 & 4 \\
\hline MOF-ERGO/GCE & $0.2-160$ & 0.016 & 43 \\
\hline HKUST-1/GCE & $12.5-275$ & 0.092 & 44 \\
\hline NiONPs-GO-CTS: EPH/GCE & $0.10-2.9$ & 6.7 & 45 \\
\hline $\mathrm{Au} / \mathrm{NPCs}-\mathrm{GCE}$ & $0.12-95.10$ & 0.049 & 46 \\
\hline $\mathrm{P}_{3} \mathrm{MT} / \mathrm{RGO} / \mathrm{GCE}$ & $0.2-2.5$ & 0.025 & 47 \\
\hline CoTPyPRu(bipy) ${ }_{2}-\mathrm{Ba} / \mathrm{GCE}$ & $1-50$ & 0.1 & 10 \\
\hline GF/UiO-66/GCE & $0.5-200$ & 0.07 & This work \\
\hline \multicolumn{4}{|l|}{ TRYP } \\
\hline MWCNTs-NHNPs-MCM-41/GCE & $0.5-50$ & 0.11 & 3 \\
\hline $\mathrm{NiO}-\mathrm{CuO}-\mathrm{GR} / \mathrm{GCE}$ & $0.3-40$ & 0.1 & 4 \\
\hline GNP-CILE/GCE & 5- 900 & 4 & 48 \\
\hline $\mathrm{SiO}_{2} / \mathrm{CPE}$ & $0.1-50$ & 0.036 & 49 \\
\hline Ce-ZnO/f-MWCNT & $0.0010-0.1$ & 0.0012 & 2 \\
\hline AgNPs/MIL-101/GCE & $1-150$ & 0.14 & 50 \\
\hline GF/UiO-66/GCE & $0.5-113$ & 0.057 & This work \\
\hline
\end{tabular}

CPE : Carbone Paste Electrode ; GR : Graphene ; ERGO : Electrochemical Reduced Grapheme oxide; GNP: Gold Nanoparticles; CILE : Carbon Ionic Liquid; GO : Grapheme oxide; CTS: Chitosan ; P3MT: Poly (3-methylthiophene); CoTPyPRu(bipy)2: Tetra(4-pyridyl) porphyrinate cobalt (I I) tetrakis [bis(bipyridine)(chloro)ruthenium(II) ; HKUST-1 : copper trimesic acid MOF 


\subsection{Real sample analysis}

To verify the practicability of the sensors, the proposed method was applied to the direct determination of AC contained in a pharmaceutical sample, and TRYP in human urine. Paracetamol 500 tablet (i.e. $500 \mathrm{mg}$ of acetaminophen/tablet) was purchased from a local drugstore. The analyte was then prepared by dilution of a known amount of tablet in deionised water and analysed using the standard addition method by successive addition of this solution in a voltammetric cell containing $\mathrm{AB}$ solution ( $\mathrm{pH}$ 4). DPV response of the analyte was recorded as shown in Figure S8 A (dashed line). This was followed by five successive additions of AC standard solution in the voltammetric cell and DPVs recorded as shown in Figure S8 A (solid lines). TRYP mixture sample was prepared by dissolving a known amount of analyte in the collected urine and analysed using the standard addition method. The sample was diluted 100 times in the voltammetric cell, and then the DPV response was recorded at GF/UiO-66/GCE (dashed line Fig. S8 B). This was followed by the successive addition of standard mixture. It can be seen that, adding successively five standard solutions containing TRYP led to an increase of the current (solid lines). The amounts of the two analytes contained in tap water were also quantified using the same method. The diluted tap water sample was added to electrolytic solution and the DPV was recorded, exhibiting two peaks corresponding to AC and TRYP (dashed line; Fig. S9). This was followed by the addition of four standard solutions containing the two analytes (solid lines, Fig. S9). From the slopes of the regression line shown in the inset, the recovery rates of the spike samples were determined and ranged between 95-107\% for both AC and TRYP.

\subsection{Stability of GF/UiO-66/GCE}

Since the procedure of electrode preparation is quite simple and rapid, it is not so important for the electrode to be stable for a prolonged time. However, the stability of the electrode was 
checked by measuring the response during two weeks, noting the electrode was stored in acetate buffer, when not in use. It was observed that the sensor retained 90 and $92 \%$ (for AC and TRYP, respectively) of its initial response after two weeks. Even after this period, the electrode was still in good shape to be used, requiring just a new calibration.

\section{Conclusion}

A graphene foam/Zr-MOF composite modified glassy carbon has been developed by a simple one-step procedure. The fabricated GF/UiO-66/GCE benefitted from the good electrocatalytic activity of the GF/UiO-66 and thus exhibited good selectivity and sensitivity for individual and simultaneous determination of AC and TRYP with low detection limits and wide concentration ranges. The fabricated electrochemical sensors were further explored for the detection of AC in a pharmaceutical preparation, and TRYP in human urine. Although uric acid was found to interfere with AC, the electrode presented here has promising applications for the determination of these analytes in biological samples and in water. The simplicity of preparation of this kind of sensor and ability to catalyse distinct reactions opens a very attractive direction in fields such as catalysis, electroanalysis and electrocatalysis.

\section{Conflicts of interest}

There are no conflicts to declare

\section{Acknowledgements}

The financial support from the ROYAL SOCIETY and UK Aid (ROYAL SOCIETY- DFID Grant $\mathrm{N}^{\circ}$ AQ 150029 - ACBI programme) is gratefully acknowledged. 


\section{References}

1 F. Patel, Medicine, Science and the Law 1992, 32, 303-310

$10.1177 / 002580249203200404$.

2 D. Naganathan, P. Thangamani, T. Selvam, T. Narayanasamy, Microchimica Acta 2018, 185, 96 10.1007/s00604-017-2641-1.

3 A. Babaei, E. Ansari, M. Afrasiabi, Analytical Methods 2014, 6, 8729-8737 10.1039/C4AY01227E.

4 B. Liu, X. Ouyang, Y. Ding, L. Luo, D. Xu, Y. Ning, Talanta 2016, 146, 114-121 10.1016/j.talanta.2015.08.034.

5 D. M. Reynolds, Water Research 2003, 37, 3055-3060 https://doi.org/10.1016/S00431354(03)00153-2.

$6 \quad$ K. D. Altria, P. Harkin, M. G. Hindson, Journal of Chromatography B: Biomedical Sciences and Applications 1996, 686, 103-110 https://doi.org/10.1016/S0378-4347(96)00037$\underline{0}$.

7 T. Todorovski, M. Fedorova, R. Hoffmann, Journal of Mass Spectrometry 2011, 46, 1030-1038 10.1002/jms.1984.

8 S. P. Sood, L. E. Sartori, D. P. Wittmer, W. G. Haney, Analytical Chemistry 1976, 48, 796-798 10.1021/ac60370a025.

9 J. C. Kemmegne-Mbouguen, L. Angnes, E. Mouafo-Tchinda, E. Ngameni, Electroanalysis 2015, 27, 2387-2398 10.1002/elan.201500110.

10 J. C. Kemmegne-Mbouguen, H. E. Toma, K. Araki, V. R. L. Constantino, E.

Ngameni, L. Angnes, Microchimica Acta 2016, 183, 3243-3253 10.1007/s00604-016-1985-2.

11 G. Aragay, F. Pino, A. Merkoçi, Chemical Reviews 2012, 112, 5317-5338

$10.1021 / \mathrm{cr} 300020 \mathrm{c}$.

12 A. Wong, A. M. Santos, T. A. Silva, O. Fatibello-Filho, Talanta 2018, 183, 329-338 10.1016/j.talanta.2018.02.066.

13 S. Cheemalapati, S. Palanisamy, V. Mani, S.-M. Chen, Talanta $\$ V 117$ 2013, 297-304.

14 C. E. Banks, T. J. Davies, G. G. Wildgoose, R. G. Compton, Chemical

Communications 2005, 829-841 10.1039/B413177K.

15 S. Stankovich, D. A. Dikin, R. D. Piner, K. A. Kohlhaas, A. Kleinhammes, Y. Jia, Y.

Wu, S. T. Nguyen, R. S. Ruoff, Carbon 2007, 45, 1558-1565

https://doi.org/10.1016/j.carbon.2007.02.034.

$16 \quad$ S. Eigler, C. Dotzer, A. Hirsch, Carbon 2012, 50, 3666-3673

https://doi.org/10.1016/j.carbon.2012.03.039.

17 S. Yang, Y. Li, S. Wang, M. Wang, M. Chu, B. Xia, Microchimica Acta 2018, 185, 112 10.1007/s00604-017-2638-9.

18 H. Gu, Y. Xing, P. Xiong, H. Tang, C. Li, S. Chen, R. Zeng, K. Han, G. Shi, ACS Applied Nano Materials 2019, 2, 6537-6545 10.1021/acsanm.9b01465.

19 L. C. S. Figueiredo-Filho, D. A. C. Brownson, O. Fatibello-Filho, C. E. Banks, Electroanalysis 2014, 26, 93-102 10.1002/elan.201300363.

20 O. M. aghi, G. Li, H. Li, , , Nature Energy 1995, 378, 703-706. .

21 C. Petit, T. J. Bandosz, Advanced Materials 2009, 21, 4753-4757

10.1002/adma.200901581.

22 M. Yoon, R. Srirambalaji, K. Kim, Chemical Reviews 2012, 112, 1196-1231

$10.1021 / \mathrm{cr} 2003147$.

23 J.-R. Li, R. J. Kuppler, H.-C. Zhou, Chemical Society Reviews 2009, 38, 1477-1504 10.1039/B802426J.

24 S.-L. Li, Q. Xu, Energy \& Environmental Science 2013, 6, 1656-1683

10.1039/C3EE40507A. 
25 Z. R. Herm, E. D. Bloch, J. R. Long, Chemistry of Materials 2014, 26, 323-338 $10.1021 / \mathrm{cm} 402897 \mathrm{c}$.

26 Q. Chen, X. Li, X. Min, D. Cheng, J. Zhou, Y. Li, Z. Xie, P. Liu, W. Cai, C. Zhang, Journal of Electroanalytical Chemistry 2017, 789, 114-122 10.1016/j.jelechem.2017.02.033.

27 R. Senthil Kumar, S. Senthil Kumar, M. Anbu Kulandainathan, Electrochemistry Communications 2012, 25, 70-73 https://doi.org/10.1016/j.elecom.2012.09.018.

28 J. Mao, L. Yang, P. Yu, X. Wei, L. Mao, Electrochemistry Communications 2012, 19, 29-31 https://doi.org/10.1016/j.elecom.2012.02.025.

29 J. J. Gassensmith, J. Y. Kim, J. M. Holcroft, O. K. Farha, J. F. Stoddart, J. T. Hupp, N. C. Jeong, Journal of the American Chemical Society 2014, 136, 8277-8282 $10.1021 / \mathrm{ja5} 006465$.

30 Z. Xu, L. Yang, C. Xu, Analytical Chemistry 2015, 87, 3438-3444 $10.1021 /$ ac5047278.

31 M. Cao, X. Yin, X. Bo, L. Guo, Journal of Electroanalytical Chemistry 2018, 824, 153-160 https://doi.org/10.1016/j.jelechem.2018.07.049.

32 Y. Zhang, A. Nsabimana, L. Zhu, X. Bo, C. Han, M. Li, L. Guo, Talanta 2014, 129, 55-62 https://doi.org/10.1016/i.talanta.2014.05.007.

33 J. Xu, J. Xia, F. Zhang, Z. Wang, Electrochimica Acta 2017, 251, 71-80 https://doi.org/10.1016/j.electacta.2017.08.114.

34 S. Rani, S. Kapoor, B. Sharma, S. Kumar, R. Malhotra, N. Dilbaghi, Journal of Alloys and Compounds 2020, 816, 152509 https://doi.org/10.1016/j.jallcom.2019.152509.

35 S. Bambalaza, H. W. Langmi, N. Musyoka, J. Ren, L. Khotseng, Materials Today: Proceedings 2018, 5, 10431-10439 10.1016/j.matpr.2017.12.323.

36 J. Ren, H. W. Langmi, B. C. North, M. Mathe, D. Bessarabov, International Journal of Hydrogen Energy 2014, 39, 890-895 https://doi.org/10.1016/j.ijhydene.2013.10.087.

37 C. Wang, R. Yuan, Y. Chai, S. Chen, Y. Zhang, F. Hu, M. Zhang, Electrochimica Acta 2012, 62, 109-115 http://dx.doi.org/10.1016/j.electacta.2011.11.115.

38 S. Luo, H. Xiao, S. Yang, C. Liu, J. Liang, Y. Tang, Sensors and Actuators B:

Chemical 2014, 194, 325-331 http://dx.doi.org/10.1016/j.snb.2013.12.108.

39 F. Xu, F. Wang, D. Yang, Y. Gao, H. Li, Materials Science and Engineering: C 2014, 38, 292-298 http://dx.doi.org/10.1016/j.msec.2014.02.017.

40 E. Laviron, Journal of Electroanalytical Chemistry and Interfacial Electrochemistry 1979, 101, 19-28 https://doi.org/10.1016/S0022-0728(79)80075-3.

41 R. C. Klet, Y. Liu, T. C. Wang, J. T. Hupp, O. K. Farha, Journal of Materials Chemistry A 2016, 4, 1479-1485 10.1039/C5TA07687K.

42 Y. Fan, J.-H. Liu, H.-T. Lu, Q. Zhang, Colloids and Surfaces B: Biointerfaces 2011, 85, 289-292 https://doi.org/10.1016/j.colsurfb.2011.02.041.

43 B. Ma, H. Guo, M. Wang, L. Li, X. Jia, H. Chen, R. Xue, W. Yang, Electroanalysis 2019, 31, 10.1002/elan.201800890.

44 F. A. Sofi, M. A. Bhat, K. Majid, New Journal of Chemistry 2019, 43, 3119-3127 10.1039/C8NJ06224B.

45 A. Martin Santos, A. Wong, A. Araújo Almeida, O. Fatibello-Filho, Talanta 2017, 174, 610-618 https://doi.org/10.1016/j.talanta.2017.06.040.

46 F. Li, R. Li, Y. Feng, T. Gong, M. Zhang, L. Wang, T. Meng, H. Jia, H. Wang, Y. Zhang, Materials Science and Engineering: $C$ 2019, 95, 78-85 https://doi.org/10.1016/j.msec.2018.10.074.

$47 \quad$ C. Li, W. Si, Y. Wu, C. Zhang, W. Lei, Q. Hao, Nano 2018, 13, 1850104 10.1142/s1793292018501047.

48 A. Safavi, S. Momeni, Electroanalysis 2010, 22, 2848-2855 10.1002/elan.201000279. 
49 M. Xu, M. Ma, Y. Ma, Russian Journal of Electrochemistry 2012, 48, 489-494 10.1134/S1023193512050126.

50 Z. Peng, Z. Jiang, X. Huang, Y. Li, RSC Advances 2016, 6, 13742-13748 10.1039/C5RA25251B. 